\title{
Modelling influenza epidemics in the relation between black smoke and total mortality. A sensitivity analysis
}

\author{
Aurelio Tobías, Michael J Campbell
}

A positive association between black smoke and total mortality has been reported in Barcelona, Spain. ${ }^{1}$ A feature of the data was sudden spikes in the mortality data resulting from influenza epidemics. Modelling approaches for weather ${ }^{2}$ and methods for removing seasonal or other long wave patterns ${ }^{3}$ have been studied, but not different methods for modelling influenza epidemics. In previous work influenza epidemics were controlled for by means of only one dummy variable, " 1 " denoting the occurrence of an epidemic and " 0 " otherwise. ${ }^{13}$ Using this approach we cannot control for the possible variability in total daily mortality within influenza epidemic periods between years. Other authors have suggested using quantitative information about influenza epidemics, say the daily number of cases of influenza. ${ }^{4}$ Our objective is to conduct a sensitivity analysis examining the effect of different methods of modelling influenza epidemics on the estimated association between black smoke and total mortality in Barcelona, in the period 1991-1995.

\section{Methods}

The mortality register supplied total daily mortality. Daily number of cases of influenza, and information about influenza epidemics was provided by the epidemiological surveillance system of the Barcelona City Council. ${ }^{5}$ A system of monitoring daily number of deaths has been shown to be useful in detecting a suspected epidemic of influenza by analysing the mortality data as a univariate time series. ${ }^{56}$ However, definition of an influenza epidemic is also based on the systematic collection and evaluation of other indicators during the active influenza season: reported influenza-like illness, home visits by general practitioners and paediatricians, and isolation of influenza viruses. Daily information on temperature and humidity was collected by the National Meteorological Institute. Levels of black smoke, 24 hour average, were obtained from the city monitoring network.

Three influenza epidemics were detected. Each year they appeared in different months, and also had different period lengths: in $1991 / 92$ there was no epidemic period; in $1992 / 93$ the period was from 31 January to 6 March 1993 (66 days); in 1993/94 from 5 December 1993 to 15 January 1994 (42 days); in 1994/1995 there was no epidemic period; and in late 1995 there was a period from 3 to 31 December (29 days). Fitting a single dummy variable for influenza in previous studies we found that it was the most significant coefficient in the Poisson model. ${ }^{1}$ However, it is possible that only one dummy variable is insufficient to model the variability in daily deaths attributable to influenza. To control it, influenza epidemics were also modelled under two alternative approaches: using three dummies, one for each epidemic period, and including the daily number of cases of influenza for every day in the study period.

Following the APHEA protocol, ${ }^{3}$ Poisson regression was used to model the daily count of deaths on air pollution, after control for weather, long term trend and season. We assess the goodness of fit looking for the model that minimises the Akaike's Information Criteria (AIC). The analyses were carried out using Stata 5.0.

\section{Results}

Table 1 shows three different ways of controlling for influenza epidemics in the relation between total mortality and black smoke. The

\begin{tabular}{|c|c|c|c|c|c|c|c|}
\hline \multirow{3}{*}{$\begin{array}{l}\text { Institute of General } \\
\text { Practice and Primary } \\
\text { Care, Community } \\
\text { Sciences Centre, } \\
\text { Northern General } \\
\text { Hospital, The } \\
\text { University of Sheffield, } \\
\text { Sheffield } \\
\text { M J Campbell }\end{array}$} & \multicolumn{7}{|c|}{$\begin{array}{l}\text { Table } 1 \text { Adjusted coefficients }(\beta) \text { and standard error (SE) of total daily mortality related black smoke. Data from } \\
\text { Barcelona, period 1991-1995 }\end{array}$} \\
\hline & & \multicolumn{2}{|c|}{$\begin{array}{l}\text { Modelling influenza with a } \\
\text { single dummy variable for } \\
\text { influenza epidemics }\end{array}$} & \multicolumn{2}{|c|}{$\begin{array}{l}\text { Modelling influenza with } \\
\text { three dummy variables for the } \\
\text { different influenza epidemics }\end{array}$} & \multicolumn{2}{|c|}{$\begin{array}{l}\text { Modelling influenza } \\
\text { with the daily number of } \\
\text { cases of influenza for } \\
\text { every day in the study } \\
\text { period }\end{array}$} \\
\hline & & $\beta(S E)$ & p value & $\beta(S E)$ & p value & $\beta(S E)$ & $p$ value \\
\hline $\begin{array}{l}\text { Correspondence to: } \\
\text { Dr Aurelio Tobías, Research }\end{array}$ & Black smoke $\left(\times 10^{4}\right)$ & $6.17(2.38)$ & 0.010 & $6.79(2.39)$ & 0.004 & $5.45(2.37)$ & 0.022 \\
\hline $\begin{array}{l}\text { Dr Aurello 10bias, Kesearch } \\
\text { Unit of Environmental and }\end{array}$ & Influenza epidemic, all period & $0.0848(0.0162)$ & $<0.001$ & & & & \\
\hline Respiratory Health, Institut & Influenza epidemic 1992/93 & & & $0.0326(0.0224)$ & 0.145 & & \\
\hline Municipal d'Investigacio & $\begin{array}{l}\text { Influenza epidemic } 1993 / 94 \\
\text { Influenza epidemic late } 1995\end{array}$ & & & $0.1660(0.0361)$ & $<0.001$ & & \\
\hline Medica, C/ Doctor Aiguader & Daily number of cases of influenza $\left(\times 10^{4}\right)$ & & & & & $2.12(0.27)$ & $<0.001$ \\
\hline 80, E-08003 Barcelona, & Degrees of freedom & 1725 & & 1723 & & 1725 & \\
\hline Spain. & Deviance & 1912.4 & & 1900.1 & & 1880.6 & \\
\hline & Mean deviance & 1.108 & & 1.102 & & 1.090 & \\
\hline Accepted for publication & AIC & 11753.6 & & 11745.3 & & 11721.8 & \\
\hline
\end{tabular}


coefficient for black smoke changed above $10 \%$ when influenza was modelled by the daily number of cases, instead dummy variables identifying epidemic periods, although standard errors were very close, and the coefficient was still statistically significant. Influenza coefficients are always statistically significant, but when three dummies are included in the model, influenza epidemic variables for each year have a different effect on total mortality, and are non-statistically significant for 1992/93 epidemic period. Using daily number of cases to control for the occurrence epidemics we have obtained a better fit to the data, in terms of a lower mean deviance and a lower AIC.

\section{Discussion}

Results obtained suggest that controlling epidemics by using the daily number of cases of influenza is more informative than using dummy variables. The residual autocorrelation structure is the same whether influenza is modelled by daily number of cases or by dummy variables. This suggests that the process for modelling epidemics may not be very sensitive to epidemic intensity. Although the magnitude of the effect of the black smoke is changed, the association with total mortality is not modified. However, changes in the black smoke coefficient, but not in the standard error, suggest that relevant explanatory variables have been mismodeled using a single dummy variable.

These findings could be extended to other pollutants and other causes. However, different models including different confounding vari- ables, give different estimates of the effect of air pollutants on health. A study in the Netherlands ${ }^{7}$ showed the disappearance of the association attributable to sulphur dioxides after an appropriate adjustment for temperature. The interpretation of such models needs care, so that it is important to state clearly in the report how the confounding variables have been modelled.

We are grateful to Ferran Ballester (IVESP) for their comments on an earlier drafts, and to the referee for his helpful suggestions. This research was done when Aurelio Tobías was visiting the Institute of Primary Care, University of Sheffield (UK).

Funding: Aurelio Tobías was funded by the British Council and by the Research Stimulation Fund by ScHARR, University of Sheffield.

Conflicts of interests: none.

1 Sunyer J, Castellsagué J, Sáez M, et al. Air pollution and mortality in Barcelona. 7 Epidemiol Community Health mortality in Barcelona. 7 .

2 Ballester F, Corella D, Perez-Hoyos D, et al. Mortality as a function of temperature. A study in Valencia, Spain, 19911993. Int F Epidemiol 1997;26:551-61.

3 Katsouyanni K, Schwartz J, Spix C, et al. Short term effects of air pollution on health: a European approach using epimiol Community Health 1996;50 (suppl 1):S12-18.

4 Ballester F, Corella D, Perez-Hoyos S, et al. Air pollution and mortality in Valencia, Spain: a study using the APHEA methodology. F Epidemiol Community Health 1996;50:52733.

5 Dominguez A, Munoz P, Martinez A, et al. Monitoring mortality as an indicator of influenza in Catalonia, Spain. $\mathcal{f}$ Epidemiol Community Health 1996;50:293-8.

6 Borrell $\mathrm{C}$, Plasència $\mathrm{A}$, Thió $\mathrm{S}$, et al. Vigilància epidemiològica de la mortalitat a partir dels enterraments. Gac Sanit 1991;5:6-16.

7 Mackenbach JP, Kunst AE, Looman CWN. Air pollution lagged effects of temperature and mortality: The Netherlands 1979-87. F Epidemiol Community Health 1995;47: $121-6$. 